\title{
Notes on transliteration and dating
}

Confronted by the range of languages employed for personal and place names across three continents, this book adopts a pragmatic approach. Personal names and technical vocabulary in Arabic and Persian are transliterated according to the International Journal of Middle Eastern Studies, but without the macron over the long vowels and the dots under selected consonants. I have not employed the plural forms of Arabic and Persian terms; plurals are indicated by the addition of an unitalicised s. The spellings of place names are generally as they appear in published archaeological reports, although I have sometimes provided ancient, medieval or modern alternatives. I have, however, imposed some standardisation: the Arabic definite article is always given as 'al-', and the Persian izafa as -'-i'. Words that appear commonly in toponyns are also rendered in a consistent manner. Thus tal is preferred to tel, tell or tall; khirbat is preferred to khirbet; and the Maghribi qsar is, in accordance with its spelling elsewhere in the Arabic-speaking world, given as qasr. The geographical scope of terms such as Greater Syria, Ifriqiya, and Khurasan is explained in the glossary. The years and centuries mentioned in the book are given according to the Common Era, with Hijri dates added in cases of objects or buildings with dated inscriptions. 